REVISTA DE DERECHO UNED, NÚM. 9, 2011

\title{
LA PROTECCIÓN DEL MENOR DESDE UN ENFOQUE DEL DERECHO CONSTITUCIONAL
}

\author{
CAYETANO NúÑEZ RIVERO \\ Departamento de Derecho Político, UNED
}

Adolfo Alonso Carvajal

Abogado. Doctor en Derecho

Resumen: Sobre la protección del menor, se incide en un enfoque propio del Derecho Constitucional, a partir de las declaraciones de los derechos humanos, tanto del ámbito europeo, latinoamericano, musulmán, como de carácter global. A este respecto, se analiza la legislación española y los principios inspiradores de la misma. Se estudian igualmente los conflictos surgidos cuando tales derechos se enfrentan a otros sistemas legales de origen musulmán, que tienen su fundamento en materia de familia en sistemas canónicos jurídicos definidos por el Quaram, los Haddit, o dichos del profeta, la Umma, o decisiones de la asamblea de los creyentes, y los dictámenes de los juristas, organizados en escuelas diferentes, que configuran la Sharia.

Palabras clave: Derechos Fundamentales, dignidad, libertad, igualdad, Quaram, Haddit, Umma, Sharia.

Abstract: On the protection of minors, affects its own approach to constitutional law, from the declarations of human rights, both European, Latin American, Muslim, and global in nature. In this regard, discusses about Spanish law and the principles thereof. They also discussed the conflicts where such rights are facing other legal systems of Muslim origin, which are based on family legal systems defined canonical Quaram, the Haddit, or sayings of the prophet, the Umma, or 
decisions the assembly of believers, and the opinions of jurists, organized in different schools, which make up the Sharia.

Key words: Fundamental Rights, dignity, freedom, equality, Quaram, Haddit,, Umma, Sharia.

Sumario: I. Introducción.-II. El sistema constitucional español de Derechos Fundamentales.-III. La dignidad, la igualdad y la Libertad en el sistema español de Derechos Fundamentales.-III.1. La Dignidad.-III.2. La Libertad.-III.3. La Igualdad.-III.4. Los Convenios internacionales sobre Derechos Fundamentales y la Constitución española.-IV. Los Derechos Fundamentales del menor en la legislación española.-IV.1. La Constitución y los derechos fundamentales de los menores.-IV.2. La catalogación de los derechos fundamentales de los menores, por medio de la Ley Orgánica 1/1996, de 14 de Enero de protección Jurídica del menor, de modificación parcial del Código Civil, y de la Ley de Enjuiciamiento Civil.-IV.3. De los convenios internacionales a partir del contenido en el artículo 3 de la Ley orgánica y del general principio constitucional sobre el valor de los tratados internacionales contenidas no solo en el artículo 10.2, sino también del artículo 96.-V. Derechos Fundamentales diferentes para diferentes sistemas de Derecho de Familia.-V.1. Derecho positivo occidental.-V.2. La «Sharia» o «Estatuto personal» Árabe.

\section{INTRODUCCIÓN}

La Convención de derechos del niño, actualmente vigente, fue aprobada por la Asamblea General de las Naciones Unidas, mediante la resolución 44/25, del 20 de noviembre de 1989; en la misma se proclama que los menores, sin discriminación de naturaleza alguna, tienen los mismos derechos que cualquier otra persona, y precisan de protección especial, de tal forma, que con respecto al menor se abandona el concepto de sujeto tutelado, para transformarlo en sujeto de derecho. Este instrumento crea también el marco de acciones para la efectividad de los derechos humanos de la niñez con claras responsabilidades para el Estado, la familia y la sociedad ${ }^{1}$.; sin embargo, actualmente, en una gran mayoría de los Estados firmantes, existen colectivos de menores, que son víctimas de un entorno poco favorable para su desarrollo, de tal forma, que el mismo no puede producirse con todas las garantías que prevé la citada Convención.

${ }^{1}$ Sobre este punto véase PEÑARANDA QuINTERo, Héctor; «El sistema venezolano para la protección integral de niños, niñas y adolescentes». Univ. Zulia. Maracaibo. 2009. 
Estos colectivos de menores pertenecientes a grupos identificados como en situación de dificultad social, atraviesan alguna de las siguientes situaciones ${ }^{2}$ :

1. Viviendo una situación de desequilibrio físico (una enfermedad o una discapacidad), psíquico (un trastorno de conducta o una psicopatología) o social (una crisis familiar, una situación de violencia).

2. Son hijos de familias, que carecen del apoyo social necesario, para cuidarles como necesitan, o son víctimas de separaciones, o divorcios, mal resueltos.

3. Viven en familias en situación de pobreza.

4. Están bajo una medida de protección jurídico-administrativa, porque se encuentran en situación de riesgo, o han sufrido abandono, malos tratos o abusos.

5. Están en riesgo de marginación, porque presentan algunos problemas de conducta, de absentismo y fracaso escolar, o porque comienzan a consumir algunas drogas, o a incurrir en pequeños delitos.

6. Son hijos de familias inmigrantes o refugiados, con todos los problemas derivados de vivir dos culturas, que no siempre se respetan entre sí.

7. Son adolescentes, que han inmigrado solos.

Existe un consenso social generalizado sobre la necesidad de que las personas, las instituciones públicas y las organizaciones sociales, contribuyan a garantizar los derechos de los menores, especialmente, su derecho a la integridad y a no sufrir torturas o tratos inhumanos y vejatorios, a su desarrollo integral como persona, y a su propia familia.

Un caso especialmente relevante en la protección del menor, es el referente a la sustracción de los mismos, especialmente en el de práctica interparental, cada vez más extendida, que se ha querido plantear desde el ámbito del Derecho Internacional Privado, sin tomar en consideración las repercusiones tanto desde el punto de vista civil, como penal o administrativo, sin tener en cuenta el carácter interdisciplinar del problema.

2 «Infancia en dificultad social: Marco conceptual y respuesta institucional». Ed «Cruz Roja Española». 2002. 
En la opinión que sostenemos, creemos que es necesario, sin prescindir del tratamiento internacionalista privado, incidir en un enfoque propio del Derecho Constitucional, a partir de las declaraciones de los derechos humanos, tanto del ámbito europeo, latinoamericano, musulmán, como de carácter global.

Para el mundo occidental, los derechos humanos suponen la concreción de las exigencias derivadas de la dignidad, la libertad y la igualdad, y su tutela constituye un elemento necesario para la propia definición estatal, como Estado Democrático y de Derecho. Pero esto no es exactamente igual para todos los Estados del mundo, y todos los derechos o todas las culturas, pues en el mundo islámico, esta tutela a partir de los valores laicos esenciales, de la dignidad, la libertad y la igualad, propios del mundo occidental, escapan en cierta medida al ordenamiento jurídico del Estado, en cuanto quedan condicionados por la existencia de la «Sharia», como verdad y limite ultimo absoluto del sistema de derechos, tanto en el ámbito familiar como en el de la persona. Esto implica la existencia de un concepto jurídico superior a la Constitución y a los derechos humanos, de tal forma, que en el mundo islámico, el cumplimiento de las constituciones, y por lo tanto de todo el sistema legal y en particular de todo el sistema jurídico de la familia, depende de la tolerancia del que detenta el poder religioso, que puede decidir qué derechos pueden ser aplicables y cuáles no, en virtud de que los mismos supongan confrontación con la Ley islámica religiosa, o Sharia.

\section{EL SISTEMA CONSTITUCIONAL ESPAÑOL DE DERECHOS FUNDAMENTALES}

En el sistema constitucional español, los derechos fundamentales y libertades públicas reconocidos en la Constitución son de aplicación directa, sin que sea necesario para su efectividad un desarrollo legislativo ${ }^{3}$. Aspecto que se desarrolla en numerosas sentencias, "La Constitución lejos de ser un mero catálogo de principios de no inmediata vinculación y de no inmediato cumplimiento hasta que sean objeto de desarrollo, es una norma jurídica, la Norma Suprema de nuestro ordenamiento jurídico a la que están sometidos los ciudadanos y los poderes públicos, a través de su vinculación inmediata. ${ }^{4}$

3 Art. 53 CE; STC 39/1983 de 17 de mayo.

${ }^{4}$ STC 16/1982 de 28 de Abril. 
Como se ha indicado, en la CE, los Derechos humanos, integran el sistema, y son de aplicación directa por los poderes públicos del Estado, sin embargo la experiencia demuestra que, siendo esto así, no siempre los poderes públicos aplican los derechos humanos, ni los derechos fundamentales contenidos en la Constitución española al «Derecho de Familia», y por extensión tampoco, a los casos de sustracción interparental de menores. De esta realidad surge la remisión como ultima ratio a la jurisdicción de los tribunales o los órganos internacionales de control de la aplicación de los derechos humanos.

Pero en lo que a España se refiere, nos encontramos dentro de las concepciones del Derecho occidental, propio de la Unión Europea, de carácter «iusromanista», y viviendo un proceso de unificación del Derecho de Familia Europeo, tanto en lo sustancial, como en los tribunales que han de aplicarlo.

Se encuentra España, por tanto, dentro de un sistema constitucional de derechos fundamentales, básicamente receptor de las declaraciones universales de derechos humanos, contando además con un desarrollo legal que tiene su fundamento, en lo que al ámbito de los menores se refiere, en el propio texto constitucional, así como en la Ley orgánica 1/1996, con un sistema de control Constitucional por medio del Tribunal constitucional, y la posibilidad, de acuerdo con la Ley Orgánica 2/1979, de 3 de Octubre, del Tribunal Constitucional. (LOTC), de la utilización del Recurso de Amparo.

El artículo 1.1. CE, relacionado con el 10.1 ponen de manifiesto, que la «dignidad de la persona, los derechos inviolables que le son inherentes,... son fundamento del orden político y de la paz social», o lo que es lo mismo son el centro de gravedad del orden jurídico, teniendo el carácter de universales y previos al propio texto constitucional, debiendo destacarse, que entre ellos se encuentra el orden jurídico familiar, y los derechos fundamentales concernientes de todos y cada uno de los miembros de la familia, menores o adultos, que son de obligatorio cumplimiento por parte de los poderes públicos.

Como ha indicado en Tribunal Constitucional en varias sentencias:

«(...)...no cabe desconocer que los derechos fundamentales responden a un sistema de valores y principios de carácter universal que subyacen en la declaración Universal de Derechos Humanos y a los diversos convenios internacionales sobre derechos humanos ratificados por España, y que asumidos como decisión constitucional básica, han de informar todo nuestro ordenamiento. ${ }^{5}$

5 (STC 21/1981, de 15 de Junio). 
Los derechos fundamentales, en su dimensión subjetiva, se mantienen y manifiestan como un presupuesto para la integración de las cualidades humanas de libertad y dignidad, con su corolario, en el ámbito del derecho de familia y de las relaciones familiares, como es el del principio de igualdad.

La igualdad es vista legalmente como un principio y un derecho fundamental, integrante del orden constitucional, y socialmente, a los efectos que aquí nos interesan, en una perspectiva sociológica de género, implicando igualdad de la hija, igualdad de la madre, igualdad de la esposa, igualdad de la pareja mujer; sin embargo, como hemos indicado anteriormente, es un concepto que en otros sistemas de configuración de los derechos humanos, de base jurídica islámica, dentro de la Shariá, no tiene la misma traslación, de tal forma, que situaciones jurídicas, que en occidente pueden considerarse como de desigualdad objetiva, son asumidas por la mujer musulmana, de manera racionalizada y estructurada lógicamente, como algo beneficioso, que tiene su fundamento en una división de los roles familiares, semejante a la existente en occidente hasta comienzos del siglo XX, pero que en todo caso, no les hace sentirse desiguales, sino diferentes al varón, a partir de diferentes roles de géneros.

Esto, que se plasma, de manera clara, y potente, en el ámbito del Derecho de Familia, es también, una realidad, en el campo de la sustracción de menores, en la interparental de menores, que no lo olvidemos, plantea diferentes concepciones de la custodia o de la patria potestad y choques importantes de sistemas jurídicos y de valores, redundantes, en la imposibilidad de la restitución o recuperación de los menores y por lo tanto, casi en relación causa efecto, con la violación de sus derechos fundamentales, en la lectura occidental de los mismos, que es diferente a la islámica, y, en el caso en particular, de menores de nacionalidad Española, en la violación, por consecuencia, de sus derechos fundamentales, recogidos en la CE.

Debemos aceptar por tanto, que nos movemos en una concepción de libertad, dignidad e igualdad de carácter Ius positivista occidental, que puede entrar en conflicto con otros conceptos de los derechos fundamentales, mas matizados que el nuestro sobre la igualdad de géneros, dentro del ámbito de las relaciones familiares en las que también se mueven las sustracciones interparentales de menores, lo que genera incompatibilidades de sistemas en materia de reconocimiento de decisiones judiciales y lo que genera que los países miembros de la liga árabe, en general, no suscriban las convenciones internacionales multilaterales, sobre traslado ilícito de menores, 
debiendo acudirse en algunos casos, a los pocos convenios bilaterales, o protocolos de intenciones existentes, que son de dificultoso cumplimiento o imposible ejecución en la práctica, por no tener conciencia o intención de aplicación interna por parte de los tribunales de justicia internos competentes para resolver el problema; y en donde la imagen de un Estado y la realidad social de ese Estado, van por caminos diferentes.

\section{III: LA DIGNIDAD, LA IGUALDAD Y LA LIBERTAD, EN EL SISTEMA ESPAÑOL DE DERECHOS FUNDAMENTALES}

El Art. 1.1. de la C.E, proclama el Estado de Derecho, lo que implica varias consecuencias:

1. La unidad de la Constitución y de todo el ordenamiento jurídico como un único cuerpo de regulación social, en valores y en organización.

2. La supremacía de la Constitución, y la vinculación de todos los poderes públicos a la propia norma suprema, y al resto del ordenamiento jurídico.

3. La preferencia, por último, de los derechos y libertadas fundamentales como clave del arco legal del Estado.

Vinculación que implica obligación en una doble dimensión, negativa, o positiva; por la obligación negativa, especialmente en lo relativo a los derechos fundamentales relacionados con la dignidad, el Estado ha de abstenerse de realizar actos normativos o de decisión, por cualquier órgano, que tengan un efecto degradante o envilecedor, mientras que por la obligación positiva, los actos han de ser ejecutados como ayuda a los ciudadanos, contra ataques o conductas de poderes públicos o de particulares, contrarios a los derechos fundamentales reconocidos en la Constitución, especialmente en lo que se refiere a la dignidad de la persona y del menor, y han de estar encaminados a poner fin activamente, mediante las decisiones correctas, a las situaciones que implican y constituyen violación de derechos fundamentales.

En la sustracción interparental de menores, las violaciones de derechos fundamentales relacionados con las «victimas» ${ }^{6}$ se proyec-

${ }^{6}$ Denominación admitida, tanto para los padres como para los menores, en el Dictamen de Naciones Unidas, caso Asensi\&República del Paraguay, 2009. 
tan hacia la obligación positiva de los Estados, vinculadas hacia la protección del valor de la dignidad personal tanto del padre como de los menores, cuyos derechos fundamentales se ven vulnerados por el Estado.

En este sentido, fue clara la primera sentencia del Tribunal Europeo de derechos humanos de Estrasburgo, en la que se condenó al Reino de España ${ }^{7}$, por vía de los artículos de las convenciones internacionales de derechos humanos, europea, relacionadas con la Dignidad de la persona.

\section{III.1. La Dignidad}

La preocupación actual del derecho internacional, por la defensa de los derechos humanos, parte de la consideración de que el hombre, por su propia naturaleza, por su propia consideración, y por su propia dignidad, posee derechos que le son inherentes y que no nacen de una concesión de la sociedad política. Es previa la dignidad, al derecho positivo, y por lo tanto este ha de positivarla a través de una serie de valores como la autonomía, la seguridad, la libertad y la igualdad, que se consagran y garantizan en el reconocimiento y protección de derechos y libertades.

Positivamente, en la medida en que todos los poderes públicos deberán asegurar el desarrollo de la dignidad humana, y negativamente, en tanto que los actos públicos, administrativos de cualquier órgano que procedan, deben evitar cualquier afectación a la misma.

Como ha afirmado el Tribunal Constitucional:

«(...) El valor jurídico fundamental de la dignidad de la persona, reconocido en el artículo 10 de la CE, constituye un germen de unos derechos, que le son inherentes al ser humano y, dentro del sistema constitucional es considerado como el punto de arranque, como el "Prius» lógico y ontológico para la existencia y especificación de los demás derechos» ${ }^{8}$. De forma que «(...) los derechos fundamentales, en cuanto proyecciones de núcleos esenciales de la dignidad de la persona, se erigen en los fundamentos del propio Estado de Derecho democrático, y no pueden ser menoscabados (...)»9.

La posición que se otorga a la dignidad de la persona en la C.E. supone la conversión en jurídico de un valor moral, y le otorga un sú-

7 Caso Iglesias Gil \&Reino de España. Sentencia de 29 de abril de 2003.

8 (STC 53/1985, de 11 de abril).

9 (STC 194/1994, de 28 de Junio). 
per-rango constitucional, del que derivan los derechos y libertades, que irradian su configuración a todo el texto constitucional. Si los derechos fundamentales, son considerados como facultades o pretensiones integrantes del status básico del individuo y como elementos imprescindibles para su desarrollo, como proyección inmediata de la dignidad de la persona, la dignidad básica de la persona, no admite discriminación alguna dada la igualdad esencial de todos los seres humanos, y esta dignidad debe de trascender las fronteras territoriales y deberá ser respetada no solo a todos los ciudadanos de un Estado, sino también a los extranjeros que se encuentren en el territorio de dicho Estado y sobre los que éste ejerce su jurisdicción ${ }^{10}$.

\section{III.2. La Libertad}

Es otro de los valores superiores del ordenamiento jurídico vinculado a la dignidad. De acuerdo con el Tribunal Constitucional:

«La Constitución al proclamar el valor superior de la libertad, está consagrando el reconocimiento de la autonomía del individuo para elegir entre las diversas opciones vitales que se le presentan de acuerdo con sus propios intereses, condiciones o preferencias. La libertad hay que entenderla como principio de autodeterminación vital en la persona» ${ }^{11}$.

$\mathrm{Al}$ igual que con la dignidad, se ha distinguido entre la libertad negativa y la libertad positiva. La libertad negativa, sería la situación en la cual un sujeto tiene la posibilidad de obrar o de no obrar, sin ser obligado a ello, o sin que se lo impidan otros sujetos, mientras que la libertad positiva, implica la situación en la que un sujeto tiene la posibilidad de orientar su voluntad hacia un objetivo, de tomar decisiones sin verse determinado por la voluntad de los otros. Se trata de distinguir entre la libertad de acción y la libertad de decisión o autodeterminación.» ${ }^{12}$

El Derecho de Libertad, se concreta en garantías individuales, como el derecho a la integridad física y moral, de preferente análisis y aplicación en el ámbito de la sustracción interparental de menores, o en libertades, como la libertad de residencia y circulación, derecho a contraer matrimonio, o la libertad religiosa, ideológica y de culto.

${ }^{10}$ O. Alzaga Villamil: Derecho Político español según las constitución española de 1978, T. I., Op. cit., pág. 223.

11 STC 132/1989 de 18 de julio.

12 N. BobBio, igualdad y libertad. Barcelona, Paidós, 1993, págs. 97 a 100. 
El TC. (STC 120/1990, de 27 de Junio) ha considerado que existen muchos derechos y libertades constitucionalmente protegidos que son proyección de la libertad entendida como valor superior, pero también ha reconocido que la libertad como valor superior no es accionable o protegible directamente sino a través de las proyecciones que de ellos se derivan, puesto que sólo esas proyecciones concretas crean derechos amparables.

\section{III.3. La igualdad}

Para el sistema constitucional Español, constituye una fórmula de convivencia con el Estado Social y Democrático de Derecho, un valor preeminente al que corresponde un rango central (STC 103/198, de 22 de noviembre); constituye una pauta de legitimación del orden jurídico en su conjunto, y debe presentarse como elemento de interpretación para el entendimiento de sus diversas concreciones.

La proclamación del artículo 1.1 de la C.E., no es una mera declaración, así mismo, el artículo 9.2 defiende la igualdad material, real y efectiva, lo que implica un elemento trasformador de la actuación estatal, y por último el artículo 14 proclama la igualdad ante la ley sin que pueda prevalecer discriminación alguna por razón de nacimiento, raza, sexo, religión, opinión o cualquier otra condición o circunstancia personal o social.

\section{III.4. Los convenios internacionales sobre Derechos Fundamentales y la Constitución Española}

La preocupación por el reconocimiento y garantía de los derechos humanos ocupa una parte importante del Derecho Internacional, en cuyo seno ha adquirido gran relevancia la dignidad del ser humano, como nuevo principio constitucional introducido por la carta de $\mathrm{Na}$ ciones Unidas en Derecho internacional y del cual se derivan importantes consecuencias jurídicas.

La STC 78/1982, de 20 de Diciembre,

«La Constitución Española se inserta en un contexto internacional en,materia de derechos fundamentales y libertades públicas, por lo que hay que interpretar sus normas en esta materia, de conformidad, con la Declaración Universal de Derechos Humanos y los tratados y acuerdos internacionales que menciona el precepto, pero no solo las normas contenidas en la Constitución sino todas las normas que integran el orde- 
namiento jurídico interno relativas de derechos y libertades que reconoce la norma fundamental.»

Normas entre las que se encuentran los propios instrumentos internacionales válidamente celebrados y publicados en España, que son elementos valiosos para configurar el sentido y alcance de los derechos que recoge la Constitución.

La dignidad del ser humano y los derechos que al derivarse de ella son inherentes al hombre son el fundamento del orden político y de la paz social, y los instrumentos internacionales que inspirados en la propia dignidad del hombre, reconocen derechos y libertades, constituyen instrumentos fundamentales y necesarios para interpretar y desentrañar el alcance y contenido de los derechos.

Cuando la Constitución proclama en su artículo 10.2:«Las normas relativas a los derechos fundamentales y a las libertades que la constitución reconoce se interpretarán de conformidad con la declaración Universal de los derechos humanos, y los tratados y acuerdos internacionales sobre las mismas materias ratificados por España», lo que hace es reconocer que llegado el momento de interpretar los preceptos constitucionales sobre derechos y libertades habrá de hacerlo en la forma que mejor se acomode a los convenios y demás instrumentos internacionales que sobre la materia haya ratificado nuestro Estado.

La remisión a los convenios internacionales no solo deriva, en el caso de la C.E., del artículo 10.2, sino también del artículo 96, cuando proclama:

«Los tratados internacionales válidamente celebrados, una vez publicados oficialmente en España, formarán parte del ordenamiento interno.Sus disposiciones solo podrán ser derogadas, modificadas o suspendidas en la forma prevista en los propios tratados o de acuerdo con las normas generales de Derecho internacional».

Ahora bien el artículo $10.2 \mathrm{CE}$, no ofrece rango constitucional a los derechos y libertades internacionalmente proclamados en cuanto no estén también consagrados por nuestra propia Constitución ${ }^{13}$; a lo que obliga es a interpretar los correspondientes preceptos de la Constitución de acuerdo con el contenido de dichos tratados o convenios.

La forma en que los instrumentos internacionales en materia de derechos reconocen y garantizan estos derechos y libertades se considera esencial para la determinación de su alcance, titularidad y la

13 STC 36/1991, de 14 de Febrero. 
posibilidad de imposición de límites o restricciones por parte de los poderes públicos.

La incorporación de España al orden internacional en materia de reconocimientos de derechos y libertades mediante la ratificación y publicación de diversos instrumentos internacionales, no constitucionaliza los derechos y libertades en ellos reconocidos, aunque si confiere un papel importante a la doctrina de los Tribunales que en estos mismos instrumentos se crean.

«El reconocimiento por España de la competencia de la Comisión Europea para conocer de las demandas sobre violación de los derechos humanos, de conformidad con lo dispuesto en el artículo 25 del Convenio, y la aceptación como obligatoria de la jurisdicción del TEDH no suponen sin embargo, que las sentencias de este tribunal tenga eficacia ejecutiva, pues de la propia regulación del convenio, y de su interpretación por el tribunal tienen carácter declarativo, y no anulan por si mismo ni modifican los actos, en este caso sentencias declaradas contrarios al convenio....Desde la perspectiva del Derecho Internacional y de su fuerza vinculante (Art 96 CE), el Convenio ni ha_introducido en el orden jurídico interno una instancia superior supranacional en el sentido técnico del término, de revisión o control directo de las decisiones judiciales o administrativas internas. ${ }^{14}$ (STC 245/1991).

Y en esta batalla está el Defensor del pueblo, como se ha indicado en las reiteradas menciones a las dificultades de ejecución de las sentencias en sus informes.

De los derechos y libertades enunciados en la Constitución, son titulares, de acuerdo con su contenido constitucional, los ciudadanos del Estado; sin embargo el carácter universal de los derechos ha implicado modificaciones importantes de la cuestión.

Existe una categoría de derechos que es la que nos interesa aquí, que pertenecen en condiciones de igualdad a los españoles y los extranjeros, y respecto de los cuáles no cabe diferencia de trato, utilizado como criterio especifico su especial vinculación con la dignidad de la persona. Dentro de este grupo de derechos, están incluidos por el pro-

14 Entre otras STEDH de 13 de Junio de 1979, caso Marckx, o STEDH de 25 de abril de 1983, caso Pakelli. No obstante los problemas planteados por la STEDH de 11 de Diciembre de 1991, caso Bultó, parecen abandonar la línea jurisprudencial anterior que mantenía la tesis declarativa, pues se reconoce un carácter definitivo, obligatorio y vinculante para el Estado, y que obliga a los poderes públicos a no permanecer impasible ante las mismas, por cuanto estas tienen unos efectos internos que obligan a respetar los derechos fundamentales de los recurrentes.

15 STC 107/1984.

16 STC 99/1985. 
pio Tribunal Constitucional el derecho a la integridad física y moral ${ }^{15}$, y también el derecho a la tutela efectiva de los jueces y tribunales ${ }^{16}$.

Los derechos constitucionales han sido objeto de clasificación, en virtud de si están vinculados a la Libertad o a la Igualdad. No es objeto de este trabajo el estudio de los Derechos fundamentales en general, sino solo de aquellos que de alguna manera, inciden en los derechos del menor y en la sustracción interparental de menores. Así destacaremos:

a) Dentro de los derechos de libertad:

- El Derecho a la integridad física y moral.

- El Derecho a la seguridad personal, que comprende las garantías procesales.

- La libertad religiosa y de culto.

- La Libertad de residencia y circulación.

- El Derecho a contraer matrimonio.

b) Dentro de los Derechos de Igualdad:

- El Derecho a la protección social, económica y jurídica de la familia.

- Los Derechos de los menores.

\section{LOS DERECHOS FUNDAMENTALES DEL MENOR EN LA LEGISLACIÓN ESPAÑOLA}

España se ha incorporado a los tratados internacionales, en particular la declaración de los derechos del niño de 20 de Noviembre de 1959, la Convención de las Naciones Unidas de los Derechos del niño de 20 de Noviembre de 1989, ratificada por España el 30 de noviembre de 1990, la resolución A 3-01722/1992 del Parlamento Europeo sobre la Carta de los Derechos del niño, y la Convención Europea sobre el ejercicio de los derechos del Niño de 19 de Abril de 1996.

Es aplicable para los menores por tanto, lo mismo que se ha predicado anteriormente para los derechos fundamentales de los adultos en nuestro sistema legal constitucional. Pero no es lo mismo, obviamente, el sujeto pasivo de derechos fundamentales del menor de edad, que el sujeto de derechos fundamentales del mayor de edad, ambos han de ser contemplados desde perspectivas diferentes, y con contenidos diferentes, con un claro principio, que ha de resolver las 
colisiones entre ambos, y que resulta preferente, encaminado a la protección de la dignidad, libertad e igualdad, del más débil, y plasmado en el principio general de la protección del interés del menor, y su defensa como preferente al interés de los adultos.

En el tratamiento de los derechos fundamentales de los menores en España, podemos destacar tres enfoques:

\section{IV.1. La Constitución y los derechos fundamentales de los menores}

La Constitución Española de 1978 al enumerar, en el capítulo III del Título I, los principios rectores de la política social y económica, hace mención en primer lugar a la obligación de los Poderes Públicos de asegurar la protección social, económica y jurídica de la familia, artículos 39.1 e integral de los hijos, artículo 39.2. y dentro de ésta, con carácter singular, la de los menores. Por otro lado, el mandato constitucional recogido en el artículo 39.3 de la C.E. proclama que los padres deben prestar asistencia de todo orden a los hijos habidos dentro o fuera del matrimonio, durante la minoría de edad y en los demás casos en los que legalmente proceda, insistiendo en el 39.4, en que los niños gozarán de la protección prevista en los acuerdos internacionales que velan por sus derechos.

Padres y poderes públicos, están obligados a la protección de la familia y de los menores; el entramado constitucional claramente optó por sobrepasar los límites del ámbito familiar privado, para construir un amplio marco jurídico de protección que vincula a todos los Poderes Públicos, a las instituciones específicamente relacionadas con los menores, a los padres y familiares y a los ciudadanos en general, sin establecer distinciones de territorialidad, según que esté en territorio español o se encuentre en el mismo temporalmente, ya por propia voluntad o ya contra su consentimiento fuera de España.

\section{IV.2. La catalogación de los derechos fundamentales de los menores, por medio de la Ley Orgánica 1/1996, de 14 de Enero de protección Jurídica del menor, de modificación parcial del Código Civil, y de la Ley de Enjuiciamiento Civil}

Las transformaciones sociales y culturales, operadas en nuestra sociedad, han provocado un cambio en el status social del niño, y 
como consecuencia de ello, se ha dado un nuevo enfoque, a la construcción del edificio de los derechos humanos de la infancia. Consecuente con el mandato constitucional y con la tendencia general apuntada, se ha llevado a cabo, en los últimos años, un importante proceso de renovación de nuestro ordenamiento jurídico, en materia de menores, de la que es muestra a Ley Orgánica 1/1996, de 14 de Enero, de protección Jurídica del menor, de modificación parcial del Código Civil y de la Ley de Enjuiciamiento Civil.

Por medio de esta Ley se Introduce en nuestro sistema legal la enumeración de los derechos fundamentales de los menores, incorporando los mismos, de acuerdo con los convenios internacionales asumidos por España.

Introduce en nuestro sistema el procedimiento actualmente vigente en materia de sustracción interparental convencional, mediante la dotación de contenido de los artículos 1901 y ss. de la Ley de Enjuiciamiento Civil de 1881, que se encontraban vacíos de contenido.

Pero sobre todo, significa un desarrollo de los derechos fundamentales de los menores, no suficientemente explicitados en la CE, aunque sí incorporados por medio de la vía de los tratados internacionales, dando un nuevo enfoque a la construcción del edificio de los derechos humanos de la infancia.

Este enfoque, que significa el pleno reconocimiento de la titularidad de derechos de los menores de edad y de la capacidad progresiva para ejercerlos reformula la estructura del derecho a la protección de la infancia vigente en España.

El desarrollo legislativo postconstitucional refleja esta tendencia, introduciendo la condición de sujeto de derechos a las personas menores de edad. Centra al menor como interés más necesitado de protección, resalta el concepto de audiencia al menor, en virtud de su suficiente juicio, algo que ya existía en nuestro sistema, y que también, ya es un principio de la Unión Europea, contenido en los Reglamentos de la UE sobre responsabilidad parental, profundizando en la tendencia anti cronológica objetiva, para ir a una dimensión del desarrollo evolutivo maduro, en el ejercicio directo de sus derechos. Las limitaciones que pudieran derivarse del hecho evolutivo deberán interpretarse de forma restrictiva. Más aún, esas limitaciones deben centrarse más en los procedimientos, de tal manera, que se adoptarán aquéllas que sean más adecuados a la edad del sujeto. El tema de la Audiencia del Menor aún está por construir en nuestro sistema legal y deberá ser objeto de preocupación posterior. De hecho, reciente- 
mente se ha planteado alguna cuestión interesante en sede de Recurso de Apelación de Audiencia provincial, que queremos incluir en esta reflexión. Se plantean ante la sala dos cuestiones que nos parecen de especial interés, a saber: a) La presencia de los letrados en la exploración de los menores; b) la grabación de estas declaraciones y entrega de las mismas a los letrados.

En relación a la primera de ella, dice la Sala que el artículo 770.4.3 LECN dispone que en las exploraciones de menores en los procedimientos civiles se garantizará por el juez que el menor pueda ser oído en condiciones idóneas para la salvaguarda de sus intereses, sin interferencias de otras personas, y recabando excepcionalmente el auxilio de especialistas cuando ello sea necesario, y en este sentido la Sentencia nos dice que,

"mal puede salvaguardarse el interés del menor si están presentes abogados de las partes, y le someten, como se pretendía, a un interrogatorio en toda regla, pues la finalidad de la diligencia es oír al menor, tener en consideración sus intereses, en cuanto se está resolviendo sobre el futuro de su vida.»

Y lo fundamenta en que el precepto claramente excluye las interferencias de otras personas.En relación a la segunda, la Sala estima correcto que se graben las audiencias a los menores, pues dice,

«es la forma idónea de que la audiencia pueda posteriormente verificar el resultado de esa exploración».

Sin embargo, la Sala estima «inadecuado que se facilite copia de esa grabación a las partes.» Y fundamenta esta decisión en que la finalidad es crear un ambiente propicio para que el menor pueda explayarse, mostrar sus sentimientos, sus ideas y sensaciones, si se le está preguntando sobre interioridades de su vida y relación con sus padres,

«es peligrosísimo "traicionarlo" posteriormente dando copia de la grabación a las partes. Involuntariamente se puede estar generando el riesgo de que uno de los progenitores, ante comentarios que no sean de su agrado, reprenda al menor, o adopte posturas contrarias a él. Y porque esa es la razón de que el precepto anteriormente mencionado haga referencia a que (...).se garantizará por el juez que el menor pueda ser oído en condiciones idóneas para la salvaguarda de sus intereses.(...). Y que mal se garantizan sus intereses si lo que era restringido al conocimiento del juez y del ministerio fiscal, se divulga posteriormente a las partes. Restricción que también se recoge en el artículo 754 del mismo texto legal con carácter general ${ }^{17}$.

17 Audiencia Provincial, Coruña, Sección: 3, No de Resolución: 295/2009, Fecha de Resolución: 03/07/2009, No de Recurso: 705/2008. 
El ordenamiento jurídico, y esta Ley en particular, refleja progresivamente una concepción de las personas menores de edad como sujetos activos, participativos y creativos, con capacidad de modificar su propio medio personal y social, así como de ser partícipes en la búsqueda y satisfacción de sus necesidades y en la satisfacción de las necesidades de los demás, y es por fin, en esta Ley Orgánica del año 1996, y no tanto en la Constitución Española de 1978, donde se combina, por una parte, la posibilidad del ejercicio de los derechos del menor, con la necesaria protección, que los mismos merecen, y que se introduce mediante la ampliación de la redacción del artículo 158 del Código Civil, respecto a las medidas que los Jueces pueden adoptar para evitar situaciones perjudiciales para los hijos.

Esta ampliación del artículo 158, dio lugar posteriormente a una segunda ampliación en materia específica de sustracción interparental de menores, vinculada con la libertad de movimientos, y de fijación de residencia, así como con determinadas limitaciones al ejercicio de la patria potestad.

Posibilidad de ejercicio que precisamente por su minoría de edad, y por las interferencias parentales, los menores no pueden ejercer plenamente, o incluso no pueden ejercer absolutamente, cuando son víctimas de un traslado de su lugar de residencia habitual, por uno de sus progenitores, con intención de apartarlo del otro.

Es de la combinación del artículo 39 2.y 3 y del artículo 158 del Código Civil, de la que pueden obtenerse los mecanismos de protección del menor, y de sus derechos fundamentales, en cualquier procedimiento de cualquier naturaleza, no solo en vía civil, sino también en vía penal ${ }^{18}$.

Es precisamente en materia de sustracción interparental de menores, en donde los convenios internacionales, han venido estableciendo un criterio cronológico inferior a la mayoría de edad de 18 años, para establecer como tope de aplicación la edad de 16 años, y también en donde se ha establecido una obligación de protección

18 Auto del Juzgado de violencia contra la mujer, numero 4 de Barcelona, Diligencias Previas 129/07, de fecha 23 de Julio del 2007: «...y no resuelve sobre el resto de medidas solicitadas al amparo del artículo 158 del Código Civil, y que se estiman necesarias a fin de asegurar su permanencia en España de conformidad con dicho artículo a la vista del conflicto existente entre las partes. En consecuencia se estima el recurso de reforma planteado tanto por la acusación particular, como por el Ministerio Fiscal en todos sus términos, de manera que se añaden al auto recurrido las siguientes medidas cautelares: 1.-Se prohíbe la salida de la menor N.H.P. del territorio español, salvo autorización judicial. 2.-Se requiere la entrega del pasaporte de la menor para su unión a autos...» 
del menor niño frente a la restitución, cual es evitarle un grave peligro para su integridad física o psíquica o no devolverle a países en los que no se respeten los derechos fundamentales.

¿Cuáles son por tanto esos derechos fundamentales de los menores, teniendo en cuenta lo anteriormente indicado, y la falta de mención constitucional específica a los derechos fundamentales de los menores?. La Ley Orgánica, a este respecto señala lo siguiente:

Artículo 3. Referencia a Instrumentos Internacionales.

Los menores gozarán de los derechos que les reconoce la Constitución y los Tratados Internacionales de los que España sea parte, especialmente la Convención de Derechos del Niño de Naciones Unidas y los demás derechos garantizados en el ordenamiento jurídico, sin discriminación alguna por razón de nacimiento, nacionalidad, raza, sexo, deficiencia o enfermedad, religión, lengua, cultura, opinión o cualquier otra circunstancia personal, familiar o social.

La presente Ley, sus normas de desarrollo y demás disposiciones legales relativas a las personas menores de edad, se interpretarán de conformidad con los Tratados Internacionales de los que España sea parte y, especialmente, de acuerdo con la Convención de los Derechos del Niño de Naciones Unidas de 20 de noviembre de 1989.

Los poderes públicos garantizarán el respeto de los derechos de los menores y adecuarán sus actuaciones a la presente Ley y a la mencionada normativa internacional.

«Artículo 4. Derecho al honor, a la intimidad y a la propia imagen.

1. Los menores tienen derecho al honor, a la intimidad personal y familiar y a la propia imagen. Este derecho comprende también la inviolabilidad del domicilio familiar y de la correspondencia, así como del secreto de las comunicaciones.

2. La difusión de información o la utilización de imágenes o nombre de los menores en los medios de comunicación que puedan implicar una intromisión ilegítima en su intimidad, honra o reputación, o que sea contraria a sus intereses, determinará la intervención del Ministerio Fiscal, que instará de inmediato las medidas cautelares y de protección previstas en la Ley y solicitará las indemnizaciones que correspondan por los perjuicios causados.

3. Se considera intromisión ilegítima en el derecho al honor, a la intimidad personal y familiar y a la propia imagen del menor, cualquier utilización de su imagen o su nombre en los medios de comunicación 
que pueda implicar menoscabo de su honra o reputación, o que sea contraria a sus intereses incluso si consta el consentimiento del menor o de sus representantes legales.

4. Sin perjuicio de las acciones de las que sean titulares los representantes legales del menor, corresponde en todo caso al Ministerio Fiscal su ejercicio, que podrá actuar de oficio o a instancia del propio menor o de cualquier persona interesada, física, jurídica o entidad pública.

5. Los padres o tutores y los poderes públicos respetarán estos derechos y los protegerán frente a posibles ataques de terceros.

«Artículo 5. Derecho a la información.

1. Los menores tienen derecho a buscar, recibir y utilizar la información adecuada a su desarrollo.

2. Los padres o tutores y los poderes públicos velarán porque la información que reciban los menores sea veraz, plural y respetuosa con los principios constitucionales.

3. Las Administraciones públicas incentivarán la producción y difusión de materiales informativos y otros destinados a los menores, que respeten los criterios enunciados, al mismo tiempo que facilitarán el acceso de los menores a los servicios de información, documentación, bibliotecas y demás servicios culturales.

En particular, velarán porque los medios de comunicación en sus mensajes dirigidos a menores promuevan los valores de igualdad, solidaridad y respeto a los demás, eviten imágenes de violencia, explotación en las relaciones interpersonales o que reflejen un trato degradante o sexista.

4. Para garantizar que la publicidad o mensajes dirigidos a menores o emitidos en la programación dirigida a éstos, no les perjudique moral o físicamente, podrá ser regulada por normas especiales.

5. Sin perjuicio de otros sujetos legitimados, corresponde en todo caso al Ministerio Fiscal y a las Administraciones públicas competentes en materia de protección de menores el ejercicio de las acciones de cese y rectificación de publicidad ilícita.

Artículo 6. Libertad ideológica.

1. El menor tiene derecho a la libertad de ideología, conciencia y religión.

2. El ejercicio de los derechos dimanantes de esta libertad tiene únicamente las limitaciones prescritas por la Ley y el respeto de los derechos y libertades fundamentales de los demás. 
3. Los padres o tutores tienen el derecho y el deber de cooperar para que el menor ejerza esta libertad de modo que contribuya a su desarrollo integral.

«Artículo 8. Derecho a la libertad de expresión.

1. Los menores gozan del derecho a la libertad de expresión en los términos constitucionalmente previstos. Esta libertad de expresión tiene también su límite en la protección de la intimidad y la imagen del propio menor recogida en el artículo 4 de esta Ley.

2. En especial, el derecho a la libertad de expresión de los menores se extiende:

a) A la publicación y difusión de sus opiniones.

b) A la edición y producción de medios de difusión.

c) Al acceso a las ayudas que las Administraciones públicas establezcan con tal fin.

3. El ejercicio de este derecho podrá estar sujeto a las restricciones que prevea la Ley para garantizar el respeto de los derechos de los demás o la protección de la seguridad, salud, moral u orden público.

«Artículo 9. Derecho a ser oído.

1. El menor tiene derecho a ser oído, tanto en el ámbito familiar como en cualquier procedimiento administrativo o judicial en que esté directamente implicado y que conduzca a una decisión que afecte a su esfera personal, familiar o social.

En los procedimientos judiciales, las comparecencias del menor se realizarán de forma adecuada a su situación y al desarrollo evolutivo de éste, cuidando de preservar su intimidad.

2. Se garantizará que el menor pueda ejercitar este derecho por sí mismo o a través de la persona que designe para que le represente, cuando tenga suficiente juicio.

No obstante, cuando ello no sea posible o no convenga al interés del menor, podrá conocerse su opinión por medio de sus representantes legales, siempre que no sean parte interesada ni tengan intereses contrapuestos a los del menor, o a través de otras personas que por su profesión o relación de especial confianza con él puedan transmitirla objetivamente.

3. Cuando el menor solicite ser oído directamente o por medio de persona que le represente, la denegación de la audiencia será motivada y comunicada al Ministerio Fiscal y a aquéllos.» 
Del anterior catálogo de Derechos Fundamentales, los contenidos en los artículos 2, 3, 4, 5 y 6,son sistemáticamente violados por los progenitores, en la sustracción interparental de menores, y el contenido en el artículo 8, no es adecuadamente respetado, por confrontar directamente con las interferencias parentales, que el menor ha sufrido, de manera que en la casi totalidad de los casos, el menor presenta una tal carencia de los otros derechos fundamentales reconocidos, que hacen que la audiencia sea insuficiente y que deba, debería, ser completada con pruebas periciales que garantizasen suficientemente el derecho del menor a ser oído.

\section{IV.3. De los convenios internacionales a partir del contenido en el artículo 3 de la Ley orgánica y del general principio constitucional sobre el valor de los tratados internacionales contenidas no solo en el artículo 10.2, sino también del artículo 96}

En particular, entrarían en aplicación. Los siguientes artículos y derechos fundamentales

a) Por vía de la Convención Internacional relativa a los Derechos del Niño de 20 de noviembre de 1989.

Artículo 9

1. Los Estados partes velarán porque el niño no sea separado de sus padres contra la voluntad de estos, excepto cuando, a reserva de revisión judicial, las autoridades competentes determinen, de conformidad con la Ley y los procedimientos aplicables, que tal separación es necesaria en el interés superior del niño. Tal determinación puede ser necesaria en casos particulares, por ejemplo, en los casos en que el niño sea objeto de maltrato o descuido Por parte de sus padres o cuando estos viven separados y debe adoptarse una decisión acerca del lugar de residencia del niño.

2. En cualquier procedimiento entablado de conformidad con el Párrafo 1 del presente artículo, se ofrecerá a todas las partes interesadas la oportunidad de participar en el y de dar a conocer sus opiniones.

3. Los Estados partes respetarán el derecho del niño que este separado de uno o de ambos padres a mantener relaciones personales y contacto directo con ambos padres de modo regular, salvo si ello es contrario al interés superior del niño. 
4. Cuando esa separación sea resultado de una medida adoptada por un Estado parte, como la detención, el encarcelamiento, el exilio, la deportación o la muerte (incluido el fallecimiento debido a cualquier causa mientras la persona esté bajo la custodia del Estado), de uno de los padres del niño, o de ambos, o del niño, el Estado parte proporcionará cuando se le pida, a los padres, al niño o, si procede, a otro familiar, información básica acerca del paradero del familiar o familiares ausentes, a no ser que ello resultase perjudicial para el bienestar del niño. Los Estados partes se cerciorarán, además, de que la presentación de tal petición no entrañe por si misma consecuencias desfavorables para la persona o personas interesadas.

\section{Artículo 10}

1. De conformidad con la obligación que incumbe a los Estados partes a tenor de lo dispuesto en el párrafo 1 del artículo 9, toda solicitud hecha por un niño o por sus padres para entrar en un Estado parte o para salir de él a los efectos de la reunión de la familia será atendida por los Estados partes de manera positiva, humanitaria y expeditiva. Los Estados partes garantizarán, además, que la presentación de tal petición no traerá consecuencias desfavorables para los peticionarios ni para sus familiares.

2. El niño cuyos padres residan en Estados diferentes tendrá derecho a mantener periódicamente, salvo en circunstancias excepcionales, relaciones personales y contactos directos con ambos padres. Con tal fin, y de conformidad con la obligación asumida por los Estados partes en virtud del párrafo 1 del artículo 9, los Estados partes respetarán el derecho del niño y de sus padres a salir de cualquier país, incluido el propio, y de entrar en su propio país. El derecho de salir de cualquier país estará sujeto solamente a las restricciones estipuladas por Ley y que sean necesarias para proteger la seguridad nacional, el orden público, la salud o la moral públicas o los derechos y libertades de otras personas y que estén en consonancia con los demás derechos reconocidos por la presente Convención.

\section{Artículo 11}

1. Los Estados Partes adoptarán medidas para luchar contra los traslados ilícitos de niños al extranjero y la retención ilícita de niños en el extranjero.

2. Para este fin, los Estados Partes promoverán la concertación de acuerdos bilaterales o multilaterales o la adhesión a acuerdos existentes. 
b) Por vía de Pacto Internacional de Derechos Civiles y Politicos, Adoptado y abierto a la firma, ratificación y adhesión por la Asamblea General en su resolución 2200 A (XXI), de 16 de diciembre de 1966, Entrada en vigor: 23 de marzo de 1976,

Artículo 23.- Observación general sobre su aplicación.

1. La familia es el elemento natural y fundamental de la sociedad y tiene derecho a la protección de la sociedad y del Estado.

2. Se reconoce el derecho del hombre y de la mujer a contraer matrimonio y a fundar una familia si tienen edad para ello.

3. El matrimonio no podrá celebrarse sin el libre y pleno consentimiento de los contrayentes.

4. Los Estados Partes en el presente Pacto tomarán las medidas apropiadas para asegurar la igualdad de Derechos y de responsabilidades de ambos esposos en cuanto al matrimonio, durante el matrimonio y en caso de disolución del mismo. En caso de disolución, se adoptarán disposiciones que aseguren la protección necesaria a los hijos.

Artículo 24.- Observación general sobre su aplicación

1. Todo niño tiene derecho, sin discriminación alguna por motivos de raza, color, sexo, idioma, religión, origen nacional o social, posición económica o nacimiento, a las medidas de protección que su condición de menor requiere, tanto por parte de su familia como de la sociedad y del Estado.

2. Todo niño será inscrito inmediatamente después de su nacimiento y deberá tener un nombre.

3. Todo niño tiene derecho a adquirir una nacionalidad.

Artículo 26.

Todas las personas son iguales ante la ley y tienen derecho sin discriminación a igual protección de la ley. A este respecto, la ley prohibirá toda discriminación y garantizará a todas las personas protección igual y efectiva contra cualquier discriminación por motivos de raza, color, sexo, idioma, religión, opiniones políticas o de cualquier índole, origen nacional o social, posición económica, nacimiento o cualquier otra condición social.

c) Por vía de la Resolución A 3-01722/1992, Carta Europea de Derechos del niño.

12. Todo niño tiene derecho a gozar de unos padres o, en su defecto, a gozar de personas o instituciones que los sustituyan. El padre y 
la madre tienen una responsabilidad conjunta en cuanto al desarrollo y educación. Corresponde a los padres en prioridad el dar al niño una vida digna y, en la medida de sus recursos financieros, los medios para satisfacer sus necesidades. Los Estados deberán asegurar a los padres la oportuna asistencia en las responsabilidades que les competen, a través de los correspondientes organismos, servicios y facilidades sociales. Los padres trabajadores deberán asimismo gozar de licencias para el cuidado de sus niños.

14. En caso de separación de hecho, separación legal, divorcio de los padres o nulidad del matrimonio, el niño tiene derecho a mantener contacto directo y permanente con los dos padres, ambos con las mismas obligaciones, incluso si alguno de ellos viviese en otro país, salvo si el órgano competente de cada Estado miembro lo declarase incompatible con la salvaguardia de los intereses del niño. Se deberán adoptar pronto las medidas oportunas para impedir el secuestro de los niños, su retención o no devolución ilegales -perpetrado por uno de los padres o por un tercero-, ya tenga lugar en un Estado miembro o en un tercer país. Los procedimientos legales adoptados deberán ser aptos para resolver las discrepancias de manera económica y expedita y deberán ser fácilmente aplicables en toda la Comunidad.

15. Toda decisión familiar, administrativa o judicial, en lo que se refiere al niño, deberá tener por objeto prioritario la defensa y salvaguardia de sus intereses. A tales efectos, y siempre que ello no implique riesgo o perjuicio alguno para el niño, éste deberá ser oído, desde el momento en que su madurez y edad lo permitan en todas las decisiones que le afecten. Con objeto de ayudar a tomar una decisión a las personas competentes, el niño deberá ser oído, especialmente en todos aquellos procedimientos y decisiones que impliquen la modificación del ejercicio de la patria potestad, la determinación de la guardia y custodia, la designación de su tutor legal, su entrega en adopción o su eventual colocación en una institución familiar, educativa o con fines de reinserción social. A este respecto, en la totalidad de los procedimientos deberá ser parte obligatoriamente el ministerio fiscal o su equivalente, cuya función primordial será la salvaguardia de los derechos e intereses del niño.

16. Todo niño cuyos padres, o uno de los padres, se encuentren cumpliendo una pena de privación de libertad, deberá poder mantener con los mismos los contactos adecuados.

Los niños de corta edad que convivan con sus madres en las cárceles deberán poder contar con las infraestructuras y cuidados oportunos. Los Estado Miembros deberán garantizar a estos niños su es- 
colarización fuera del ámbito carcelario. Los Estados deberán fomentar, siempre que sea posible y de acuerdo con las legislaciones nacionales y los convenios internacionales, la adopción de los niños que se encuentren en su territorio, previa autorización de sus padres o tutores o tras un período de abandono efectivo definido por la ley. Los niños abandonados, así como los niños privados definitiva o temporalmente de su medio familiar, deberán poder gozar en todo caso de una protección y una ayuda especiales. Todo niño tiene derecho a vivir con sus padres naturales, legales o adoptivos.

d) Por vía del Convenio Europeo para la Protección de los Derechos Humanos y Libertades Fundamentales, de 4 de Noviembre de 1950, ratificado por España con fecha 26 de septiembre de $1979^{19}$.

Artículo 8. Derecho al respeto a la vida privada y familiar.

1. Toda persona tiene derecho al respeto de su vida privada y familiar, de su domicilio y de su correspondencia.

2. No podrá haber injerencia de la autoridad pública en el ejercicio de este derecho, sino en tanto en cuanto esta injerencia esté prevista por la ley y constituya una medida que, en una sociedad democrática, sea necesaria para la seguridad nacional, la seguridad pública, el bienestar económico del país, la defensa del orden y la prevención del delito, la protección de la salud o de la moral, o la protección de los derechos y las libertades de los demás.

Cuando los autores doctrinales se acercan al hecho jurídico, de la sustracción interparental de menores, lo hacen, desde la teoría del derecho internacional privado, sin embargo, y esta es la tesis que defendemos, se nos presenta un fenómeno jurídico muy complejo, en el que no sólo están presentes elementos internacionales, sino también, elementos de derecho interno, elaborados por medio de los procedimientos de familia conexionados con la sustracción interparental de menores, a priori o a posteriori, de su consumación por uno de sus progenitores, con posible trascendencia penal, y civil indemnizatoria por los daños morales y de todo tipo sufridos, y con responsabilidad directa de la Administración del Estado, posible por inadecuada actuación.

Pero, también en estos hechos hay una clara dimensión de derechos fundamentales trasgredidos, tanto de los adultos, del progenitor

19 BOE 10 de octubre de 1979. Revisado en conformidad con el Protocolo $\mathrm{n}^{\circ} 11$ (Fecha de entrada en vigor 1 de noviembre. 
dejado atrás, como del menor, separado abruptamente de su otro progenitor y del lugar de su residencia habitual, en donde tenía desarrolladas todas sus facetas educacionales y sociales. Esta dimensión, es a su vez doble, por un lado, desde el punto de vista de las autoridades del Estado y del cumplimiento de sus obligaciones procesales relacionadas con un proceso en plenas garantías y sin dilaciones indebidas, y por el otro relacionado con los derechos basados en la dignidad, la igualdad y la libertad, y en los derechos de los menores de tener a su disposición todo el contenido de relaciones familiares posibles que les lleve a ser personas formadas y solidarias integradas en la sociedad.

La razón de la ausencia de una mayor trascendencia de los principios que hoy conforman lo que serían los actuales «Principios Generales del Derecho», como fuente, a través de las constituciones y de los convenios internacionales de derechos humanos, es doble, una, el propio desconocimiento o falta de sensibilidad, salvo excepciones contadas, de los juzgados de instancia y tribunales de la jurisdicción ordinaria, para tener en cuenta directamente, en la decisión de estos casos, los principios constitucionales o de los convenios internacionales; normalmente no se encuentra mención alguna en los textos de las decisiones judiciales sobre ellos, y, segunda, la falta de compromiso real del sistema judicial con la adopción de medidas efectivas de protección de la familia y del menor sustraído o que va a ser sustraído, con conocimiento previo razonable de que esto se va a producir. Pero también, el agotamiento procesal de las partes, personal, económico, moral, de enorme coste económico, que hace que el tiempo transcurra integrado en la maquinaria ordinaria de la justicia, y que llegado el momento final de acudir a los ámbitos constitucionales, por medio del Recurso de Amparo, sea contabilizado en años, por lo que el menor posiblemente se encuentre integrado en su nuevo medio, con una duración de procedimiento también largo, y que en lo que se refiere a las jurisdicciones internacionales, propia de derechos humanos, se produzca un agotamiento, aunque la experiencia dice que las que llegan a esas jurisdicciones, normalmente prosperan.

En el presente trabajo, pretendemos tratar la sustracción interparental de menores, desde la complejidad técnica práctica, pero también desde el llamamiento a la anticipación de la tutela de los derechos fundamentales, de los menores y de los adultos, para que los tribunales adopten las decisiones adecuadas a la protección de estos menores, sin dilaciones indebidas y con la valentía debida. 
En el enfoque que se ha venido haciendo, los derechos fundamentales, no han sido tema prioritario en el tratamiento de la sustracción interparental de menores, ya que el problema se ha visto en clave de Derecho Internacional Privado.

En resumen, y para el adecuado tratamiento de los derechos fundamentales en la sustracción interparental de menores, nos encontramos de lleno en un problema que afecta directamente a los valores de dignidad, igualdad, y libertad, de las personas adultas víctimas de un tipo de comportamiento de esta naturaleza, de clara sensibilidad constitucional, encajados dentro del Título I de la Constitución, y recibidos por vía de los convenios internacionales suscritos por España, en especial las declaraciones de Derechos Humanos de Naciones Unidas, y La Convención Europea de Derechos Humanos, que hace que lleguen por vía de la protección de los derechos de libertad, como los de tutela judicial efectiva, el derecho a la integridad física y moral, la libertad religiosa y de culto, libertad de residencia y circulación, libertad de contraer matrimonio, y de la protección de los derechos de igualdad, protección de la familia y derechos de los menores, a los circuitos jurisdiccionales del amparo constitucional, y sus instancias conexas supranacionales, como el Tribunal europeo de Derechos Humanos de Estrasburgo, para el ámbito europeo, el Comité de Naciones Unidas para el pacto de derechos civiles, para el ámbito mundial sujeto a las declaraciones de Naciones Unidas sobre Derechos Fundamentales, o la Corte Interamericana ${ }^{20}$, para el ámbito iberoamericano, con un progresivo avance, desde el valor meramente declarativo e indemnizatorio, hasta el valor modificativo o anulatorio, per se, de las sentencias nacionales.

La diferencia esencial se encuentra entre el mundo musulmán y el mundo occidental. derivado de la existencia de dos concepciones sobre los derechos humanos, y que en el caso de la sustracción interparental de menores, nacidos de relaciones mixtas de mujer no musulmana y hombre musulmán, generalmente, hacen extremadamente difícil, además de por cuestiones propias de sistemas jurídicos internos, la conciliación y resolución de los casos desde la óptica de los derechos humanos.

La reivindicación de los derechos humanos, debe serlo, por lo tanto, hacia el interior, hacia las consecuencias de la aplicación o no en el ámbito interno del derecho Español de las normas constitucio-

${ }^{20}$ La Opinión Consultiva 17 del año 2002 de la Corte Interamericana, denominada «Sobre la Condición Jurídica y Derechos Humanos del Niño», entre otros. 
nales, y hacia el exterior por los pronunciamientos declarativos de las organizaciones supranacionales internacionales de derechos humanos violados, durante y a lo largo de las tramitaciones de los diferentes procedimientos de derecho interno para proteger los derechos fundamentales de un menor amenazado de sustracción y cuáles sean estos derechos, y posteriormente para el control de la aplicación que hace el Estado de recepción del menor sustraído para proteger los derechos de ese menor; pero estableciendo la salvedad, de que el problema es diferente cuando se enfrentan dos concepciones diferentes de derechos humanos, como son las del mundo no musulmán y las del mundo islámico, que hace que lo que puede ser violación de los principios de la dignidad, la igualdad y la libertad en un sistema, para el otro no lo sea, o viceversa.

\section{DERECHOS FUNDAMENTALES DIFERENTES PARA DIFERENTES SISTEMAS DE DERECHO DE FAMILIA}

En nuestro ordenamiento jurídico partimos de la perspectiva de que los Derechos fundamentales, se encuentran incorporados en la C.E., y es por lo tanto una visión laicista del derecho, sin conexión, incluso por la vía del Derecho Natural, de lo que pueda significar una aproximación canónica al derecho procedente o proveniente de confesión religiosa alguna.

El Estado Español, como los Estados miembros de la Unión Europea, o de origen occidental, salvo la más significativa posición de Polonia o de Irlanda, son Estados de base civil laica ${ }^{21}$, y alejados de referencias religiosas o iusnaturalistas como última ratio de aplicación.

Sin embargo, en el Derecho de Familia surge el conflicto cuando la concepción indicada, definida por una organización jurídica con la base en una organización política laica estructurada en la Ley, que tiene como subsidiaria a la costumbre y los principios generales del Derecho, que no se sustentan en un origen religioso, se enfrenta a otros sistemas legales de origen musulmán, que tienen su fundamento en materia de familia en sistemas canónicos jurídicos defini-

${ }^{21}$ Respecto al Estado Español, referido a este caso concreto, aunque en un sentido más amplio no sería posible utilizarlo, debiendo emplear el de «no confesional»; véase sobre este punto, NúÑEZ RIVERo, Cayetano, «El Estado Laico en los orígenes del Estado Constitucional»; Rev. Encuentros en Catay, ${ }^{\circ}$ 23. Univ. Funjen. Rep China; véase del mismo autor, "La Libertad religiosa», en El sistema constitucional de derechos y libertades según la jurisprudencia de Tribunal Constitucional»; Ed. Universitas. 2006. págs. 141-159. 
dos por el Quaram, los Haddit, o dichos del profeta, la Umma, o decisiones de la asamblea de los creyentes, y los dictámenes de los juristas, organizados en escuelas diferentes, que configuran la Sharia.

Es preciso analizar, pues, los derechos fundamentales del mundo positivo laicista occidental, y los derechos fundamentales del mundo musulmán de base canónica y religiosa, a través de la Sharia.

\section{V.1. Derecho positivo occidental}

Europa se ha procurado instrumentos jurídicos para la restitución de los menores trasladados dentro de sus fronteras interiores. El Convenio Europeo relativo al reconocimiento y ejecución de decisiones, en materia de custodia de menores así como al restablecimiento de dicha custodia hecho en Luxemburgo el 20 de Mayo de 1980, fueron los más importantes, con posterioridad cabe destacar los Reglamentos Comunitarios 1347/2000 del Consejo de 29 de Mayo del 2000, y el de 2201/2003.

Junto con otros países extracomunitarios, los Estados de la Unión Europea, se han incorporado, desde hace mucho tiempo a los trabajos de la conferencia de la Haya, que en este punto en concreto, dieron lugar al convenio hecho en la Haya el 25 de Octubre de 1980, sobre los aspectos civiles de la sustracción internacional de menores, un convenio más flexible, que no sigue el criterio del reconocimiento de resoluciones, ni necesita una resolución judicial o administrativa de custodia para ser aplicado ${ }^{22}$.

Como se indicó anteriormente, las Declaraciones y Convenios suscritos por el Estado español se reciben en nuestro sistema legal español, por medio de los derechos fundamentales recogidos en la CE de 1978, y en última instancia por el catálogo de derechos recogido en la Ley Orgánica del Menor.

En este esfuerzo internacional colectivo, Europeo y mundial, tanto en materia de derechos humanos como en materia de derecho de familia, era llamativa, y es indicativa, la ausencia de Países Árabes.

${ }^{22}$ Podemos destacar como las más importantes declaraciones de Derechos $\mathrm{Hu}$ manos, tanto de aduiltos como de niños, las siguientes: 1924 Declaración de Ginebra sobre los Derechos del Niño; 1948. ONU. Declaración Universal de Derechos Humanos; 1950. Convención Europea de Derechos Humanos; 1959. ONU. Declaración de Derechos del Niño: 1966. ONU. Pactos Internacionales de Derechos Civiles y Políticos, y de Derechos Económicos, sociales y culturales y 1989. ONU. Convención sobre los Derechos del Niño. 
Para tratar de mejorar la situación, la opción europea de trabajo ha sido la búsqueda del derecho convencional multilateral, vía Convenio de la Haya de 1980, sobre los aspectos civiles de la sustracción interparental de menores, y en lo que se refiere al derecho islámico, o de definición musulmana, la búsqueda de acuerdos. Sobre este punto debe destacarse que varios estados europeos han suscrito acuerdos bilaterales con Estados árabes ${ }^{23}$.

En materia de Derecho de familia, la contradicción a resolver está entre la "Sharia», oriental, que vive ahora una interpretación mucho más rígida que la que históricamente, los clásicos musulmanes le habían dado ${ }^{24}$, y el "positivismo legal», occidental, evolutivo. Este conflicto también existe, en el secuestro interparental de menores, y está influenciado por la concepción de ambos sistemas sobre el menor y las relaciones de custodia.

\section{V.2. La «Sharia» o «Estatuto personal» Árabe}

El concepto de «Derechos Humanos», en la acepción de los mismos que se maneja en occidente, es ajeno al Mundo Islámico. En estos Estados el Derecho Constitucional está condicionado por el Derecho Islámico, primando en muchos casos, éste sobre aquél. No obstante lo indicado, en las últimas décadas, como consecuencia de una cada vez más creciente demanda interior y por la presión internacional, el mundo árabe se ha interesado por ellos; a este respecto, cabe destacar la $19^{\text {a }}$ Conferencia Islámica de Ministros de Asuntos Exteriores, en la resolución n ${ }^{\circ}$ 49/19-P. que acordó la promulgación de la Declaración de El Cairo sobre Derechos Humanos en el Islam, (DDHi) aprobada en la Conferencia de El Cairo del 9 al 14 de muharram de 1411 (31 de julio-5 agosto 1990), que significa una guía para los países de confesionalidad islámica del Estado.

"Consciente de la dignidad del ser humano en el Islam, en tanto que representante de Allah en la tierra; reconociendo la importancia de promulgar un documento sobre Derechos Humanos en el Islam, que sirva de guía a los Estados miembros en los diferentes aspectos de la vida; tras

${ }^{23}$ A modo de ejemplo podemos destacar el suscrito por España con Marruecos de 30 de Mayo de 1997 sobre asistencia judicial, reconocimiento y ejecución de resoluciones judiciales en materia de derecho de custodia, y derecho de visita y devolución de menores; Francia presenta tres convenios bilaterales, con Marruecos, Argelia y Túnez, de los años 1981, 1982 y 1988. El Reino Unido cuenta con otros tantos protocolos con estados islámicos.

${ }^{24}$ A este respecto, es necesario referirse a los antiguos jurisconsultos arábigos andaluces, como Baqui Ibn Majlab, Yusuf Ibn Yahaya, etc. 
haber examinado las diferentes etapas del proyecto de dicho documento, así como el informe de la Secretaría General al respecto; y tras estudiar el informe de la Comisión de expertos legales celebrada en Teherán del 26 al 28 de diciembre de 1989, acuerda promulgar la Declaración de El Cairo de los Derechos Humanos en el Islam, la cual proveerá las pertinentes orientaciones generales para los Estados miembros en el ámbito de los Derechos Humanos.»

La Declaración de El Cairo ha supuesto el intento más serio de abordar la cuestión de los Derechos Humanos en el mundo islámico, intentando superar el largo conflicto existente entre los Estados musulmanes y la Declaración Universal de los Derechos Humanos de la ONU. Conflicto que puede resumirse en las Declaraciones que hiciera en 1948 el Ulema paquistaní Al-Maududi,

«No es competencia humana el decidir el alcance y propósito de nuestra existencia, o establecer siquiera los límites de nuestra autoridad secular. Nadie tiene el derecho de tomar estas decisiones por nosotros. Este derecho pertenece exclusivamente a Dios. El principio de la Unicidad de Dios priva de todo sentido al concepto de la soberanía legal y politica de los seres humanos. Ningún individuo, familia, clase o raza puede ponerse por encima de Dios. Sólo Dios es el legislador y sus mandamientos constituyen la ley del Islam» 25 .

No obstante, a pesar de como se ha indicado anteriormente, la Declaración de El Cairo ha significado un intento considerable para superar la contradicción de pertenecer a las Naciones Unidas y no acatar la Declaración de los Derechos Humanos de la misma, negativa, que entre otros aspectos se derivaba de artículo 18 de la Declaración de Naciones Unidas, que proclama la libertad religiosa,

«Toda persona tiene derecho a la libertad de pensamiento, de conciencia y de religión; este derecho incluye la libertad de cambiar de religión o de creencia, así como la libertad de manifestar su religión o su creencia, individual y colectivamente, tanto en público como en privado, por la enseñanza, la práctica, el culto y la observancia» ${ }^{26}$.

Sin embargo, la citada Declaración de el Cairo, marcará los límites del ejercicio de los Derechos Humanos en el mundo islámico, resaltando su diferente concepción con respecto a los Estados de Derecho occidentales, así en el artículo 24 se proclama que,

"Todos los derechos y deberes estipulados en esta declaración están sujetos a los preceptos de la Sharia islámica», de tal forma que su

${ }^{25}$ Véase al respecto, Alonso CARvaJal; Adolfo; «Los Derechos Fundamentales en la sustracción de menores»; UNED. Fac. de Derecho. Madrid, 2009. pág. 614.

${ }^{26}$ Debe recordarse, que la práctica del ateísmo o el abandono de la religión musulmana está castigada en determinados Estados islámicos con la pena de muerte. 
aplicación queda supeditada a la confesionalidad excluyente de los Estados islámicos ${ }^{27}$, lo que queda expuesto de forma diáfana en el artículo 25,

«La Sharia Islámica es la única fuente de referencia para la aclaración o interpretación de cualquiera de los artículos del presente documento».

El tema es profundamente complejo, y lleno de tensiones, como evidencia el hecho de que las Naciones Unidas se han visto también en la necesidad de organizar, por medio de la Alta Comisionada de las Naciones Unidas para los derechos humanos y la Conferencia Islámica el seminario «Enriquecer la universalidad de los derechos humanos: perspectivas islámicas sobre la Declaración Universal de Derechos Humanos», celebrado en Ginebra los días 9 y 10 de noviembre de 1998, y posteriormente, aprobar una resolución ${ }^{28}$, «Sobre la "difamación de las religiones», en la que se ve en la necesidad de pedir respeto a las comunidades religiosas ante los estereotipos.

«Destacando que las organizaciones no gubernamentales, los órganos y las comunidades religiosas tienen una función importante que desempeñar en el fomento de la tolerancia y la protección de la libertad de religión o las convicciones;

1. Expresa su profunda preocupación ante la creación de estereotipos negativos respecto de las religiones;

2. Expresa también su profunda preocupación por el hecho de que con frecuencia se asocia, sin razón, el Islam a las violaciones de los derechos humanos y al terrorismo;

3. Expresa su preocupación por toda forma de utilización de los medios de difusión impresos, audiovisuales, electrónicos o de cualquier otra indole para incitar a la comisión de actos de violencia, xenofobia u otros actos conexos de intolerancia y discriminación contra el Islam o cualquier otra religión;

4. Insta a todos los Estados a que, en el marco de su ordenamiento jurídico nacional y de conformidad con los instrumentos internacionales

${ }^{27}$ No obstante, debe indicarse, que el concepto de confesionalidad excluyente del Estado, aunque con matices diferentes a lo que acontece actualmente en el mundo islámico, se proclamó en primer constitucionalismo español e hispanoamericano, tal es el caso del Estatuto de Bayona de 1808, la Constitución de Cádiz de 1812, La Constitución venezolana de 1811, Nueva Granada de 1832, Boliviana de 1826, Pacto social del 1diciembre de Cosa Rica etc.; proclamación que de alguna forma recortaba ampliamente el ejercicio de los derechos de libertad de conciencia expresión etc.; véase al respecto, Núñez Rivero, Cayetano y Núñez Martínez, Maria; «Iglesia y religión en los primeros textos constitucionales hispanoamericanos». Rev. Nueva Época $\mathrm{n}^{\circ} 28$, 31 y ss. Universidad Libre. Bogotá Colombia.

${ }_{28}$ Resolución 2000/84, «Difamación de las Religiones», 26 Abril 2000. 
de derechos humanos, adopten todas las medidas apropiadas para combatir el odio, la discriminación, la intolerancia y los actos de violencia, intimidación o coacción motivados por la intolerancia religiosa, incluidos los ataques a los lugares religiosos, y para fomentar la comprensión, la tolerancia y el respeto en cuestiones relacionadas con la libertad de religión o de creencia;

5. Invita a los gobiernos y a las organizaciones intergubernamentales y regionales a que comuniquen su opinión sobre las perspectivas religiosas de combatir el racismo a la Secretaria General de la Conferencia Mundial contra el Racismo, la Discriminación Racial, la Xenofobia y las Formas Conexas de Intolerancia e invita a la Secretaria General de la Conferencia Mundial a que presente esas aportaciones a la Conferencia Mundial en su proceso preparatorio;

6. Pide al Relator Especial sobre la intolerancia religiosa y al Relator Especial sobre las formas contemporáneas de racismo, discriminación racial, xenofobia y formas conexas de intolerancia que tengan en cuenta las disposiciones de la presente resolución al presentar sus informes a la Comisión».

Sobre la concepción del sistema de valores en lo que respecta a libertad, igualdad y dignidad en el mundo islámico respecto a la familia y la niñez, citamos a continuación los artículos más representativos al respecto de la Declaración citada.

Artículo 4.

Todo ser humano es acreedor de una inviolabilidad sagrada. Proteger su buena fama en vida y tras la muerte, así como su cadáver y su tumba, será una obligación de la sociedad y los respectivos Estados.

\section{Artículo 5.}

a) La familia es el fundamento de la sociedad, y el matrimonio es el fundamento de la familia. Los hombres y las mujeres tienen el derecho de casarse, $y$ sin su consentimiento no es posible restricción alguna basada en la raza, el color o la nacionalidad.

b) La sociedad y el estado eliminarán los obstáculos para el matrimonio y lo facilitarán, protegiendo y salvaguardando a la familia.

Artículo 6.

a) La mujer es igual al hombre en dignidad humana, y tiene tantos derechos como obligaciones; goza de personalidad civil así como de ulteriores garantías patrimoniales, y tiene el derecho de mantener su nombre y apellidos.

b) Sobre el varón recaerá el gasto familiar, así como la responsabilidad de la tutela de la familia. 


\section{Artículo 7.}

a) Todo niño, desde su nacimiento, tiene derecho a [sus] dos progenitores. La sociedad y el estado proveerán cuidado, educación y asistencia material, sanitaria y educativa; asimismo se protegerá al feto y a su madre, proporcionándoles cuidado especial.

b) Los padres, y todo aquel que ocupe su lugar, tienen derecho a elegir el tipo de educación que deseen para sus hijos, siempre que se tengan en cuenta sus intereses y su futuro a la luz de los valores morales y de las prescripciones de la Sharia.

c) Los progenitores tienen derechos sobre sus hijos, así como los parientes tienen derechos sobre los suyos, de acuerdo con los preceptos de la Sharia.

Artículo 11.

a) El ser humano nace libre. Nadie tiene el derecho de esclavizarlo, someterlo, sojuzgarlo o explotarlo. No hay sumisión sino hacia Allah el Altísimo.

En materia de Estatuto personal, existe una base interpretativa en la que el punto de inflexión es la religión de los cónyuges, de tal manera que el concepto de la "salvaguardia de la fe musulmana», puede ser, en el actual estado de la cuestión, un elemento interpretativo preferente, frente al elemento interpretativo del «interés del menor», tal y como en occidente lo entendemos. En Europa tampoco se ha sido ajeno históricamente, a este criterio, como cuando hasta hace 25 años,en algunos países occidentales primaba, incluso como causa de nulidad del matrimonio, el «bonun Fidei» católico. 